\title{
CAPITONNAGE VERSUS NON-CAPITONNAGE SURGERY FOR PULMONARY HYDATID CYST: A HEAD TO HEAD STUDY
}

\author{
GONI MO ${ }^{1}$, KARIM MF $^{2}$, ALAM MK ${ }^{3}$, CHOWDHURY GMA $^{4}$, AHSAN $\mathrm{S}^{5}$

\begin{abstract}
:
Background: Hydatid disease is a zoonotic disease caused by Echinococcus granulosus. In humans, lungs are the second common organ involved after liver. Surgical treatment is considered gold standard. Different surgical techniques has developed. However, head to head comparison of these has not yet been done in our country.
\end{abstract}

Methods: A prospective randomized study was done in the Department of Thoracic Surgery, National Institute of Diseases of the Chest and Hospital between July 2004 and June 2006. Patients with pulmonary hydatid disease were offered two surgical techniques, enucleation with or without capitonnage. Group I was offered enucleation of cyst with closure of bronchial opening. Group II was offered enucleation of cyst with capitonnage.

\begin{abstract}
Results: 43 patients (age range 7 - 45 years, mean 25 years) having hydatid disease of the lung were enrolled in the study. Group I involved 23 patients, Group II involved 20 patients. There were 15 males and 28 females. Presenting complaints were chest pain [76.7\%], cough without sputum [46.5\%], haemoptysis [30.2\%], respiratory distress [27.9\%], cough with sputum [11.6\%] while 23.2\% were asymptomatic. The right lung was affected more [65.11\%] than left lung [23.3\%] and bilateral disease was found in 11\%. Postoperatively, in group I, 12.9\% developed air-leakage, 4.3\% wound infection. In group II, 20\% developed air-leakage, 5\% haemorrhage and 5\% empyema. None of the patient in the former group had to stay in the hospital for $>15$ days, where as 10\% of the latter group had to stay in hospital for $>15$ days. The hospital stay was found to be significantly higher in the latter group compared to the former group ( $p<0.05)$. There was no significant difference between groups in the development of haemorrhage, empyema, wound infection and broncho-pleural fistula. There was also no significant difference in the rate of recurrence. No anaphylaxis or death occurred in either group.
\end{abstract}

Conclusion: Capitonnage offered no added benefit rather increasing complications. So enucleation followed by closure of bronchial opening may be a reasonable approach.

Key words: Hydatid cyst, Capitonnage, Lung.

J Dhaka Med Coll. 2014; 23(1) : 94-101.

\section{Introduction}

Pulmonary hydatid cyst is a zoonotic disease with worldwide distribution. Hydatidosis remains endemic to many parts of the world, most notably the Mediterranean region, Australia, New Zealand, the Middle East, Turkey and South America. In areas where hydatid disease is endemic, it is still a major public health problem. Most individuals who contract this parasite are young and majority of patients are less than 40 years of age ${ }^{1}$. In man, hydatid disease affects the liver in 50 to $60 \%$, the lung in 18 to $35 \%$ of cases. The lungs are the second most common sites of lodgment of the parasite. Pulmonary hydatid disease affects the right lung in $60 \%$ of cases, $30 \%$ exhibit multiple pulmonary cysts, $20 \%$ bilateral cysts and $60 \%$ are located in the lower lobes ${ }^{2}$.

Diagnosis of pulmonary hydatid cyst is generally based on clinical, serological and

1. Dr. Md. Osman Goni, Department of Thoracic Surgery, Dhaka Medical College Hospital, Dhaka.

2. Dr. Fazal Karim, Department of Hepatology, Sir Salimullah Medical College \& Mitford Hospital, Dhaka.

3. Dr. Md. Kamrul Alam, Department of Thoracic Surgery, Dhaka Medical College Hospital, Dhaka.

4. Dr. GM Akbar Chowdhury, Department of Thoracic Surgery, Dhaka Medical College Hospital, Dhaka.

5. Dr. Shafiqul Ahsan, Department of Thoracic Surgery, Dhaka Medical College Hospital, Dhaka.

Correspondence: Dr. Fazal Karim, Department of Hepatology, Sir Salimullah Medical College \& Mitford Hospital, Dhaka. 
radiological findings. Small simple cyst located peripherally usually remains asymptomatic. Symptomatic patients may present with chest pain, cough, haemoptysis, dyspnea, fever and respiratory distress ${ }^{1}$. Conventional radiography is routinely employed for diagnosis of the disease in our hospital. Round homogenous opacities in the lung parenchyma are characteristic of simple uncomplicated hydatid cyst, the water lily or signet ring sign is characteristic of perforated cyst. CT scan of the chest and upper abdomen may be helpful in establishing diagnosis in complicated cysts. Inverse crescent sign, signet ring sign, high CT density and thick wall can be recognized as features of pulmonary hydatid cyst on $\mathrm{CT}^{3}$.

In management of pulmonary hydatid disease, Albendazole has been used with promising result but definitive treatment still remains surgery. Different surgical techniques has developed. These are radical surgery, laparoscopic surgery, minimally invasive methods.

Minimally invasive technique like therapeutic aspiration of echinococal cyst is being performed in liver cyst, but this is not suitable for pulmonary cyst. It may be performed in adjunct to Albendazole treatment in a patient with a large recurrent, isolated pulmonary echonococcal cyst for whom traditional therapy may result in severe morbidity ${ }^{2}$.

Common surgical methods for dealing with pulmonary hydatid cysts is enucleation of intact cysts. Needle aspiration is a useful adjunctive procedure in the surgery done if there is high tension inside the cyst or there is more than three or four cyst in one lung. Closure of the bronchial opening is done by muscle pledgeted suture or by simple 3-0 silk. After bronchial opening closure of the remaining cavity can be done by capitonnage. In capitonnage the residual cavity is obliterated by imbricating sutures from within (separate purse String sutures that is places into the cavity from deepest level to the surface). The impact of capitonnage on surgical outcome is unknown and the technique continues to be performed at the choice of the surgeon ${ }^{5}$. Some surgeons preferred to keep the cavity open after closing of the bronchial opening. Other methods like cystotomy with or without capitonnage, wedge resection, segementectomy, lobectomy, pneumonectomy along with decortication may be done. Post-operative complication are pronged air leak (air leak $>7$ days), empyema and wound infection ${ }^{5}$.

Pulmonary Hydatid cyst is not uncommon in our country. National Institute of Diseases of the Chest and Hospital (NIDCH), is the only government level post-graduate chest hospital in Bangladesh. So patients were referred from all over the country. Lot of surgery is being performed on pulmonary hydatid cyst in this hospital yearly. However no study was done to compare capitonnage and non capitonnage procedure for pulmonary hydatid cyst surgery in Bangladesh.

\section{Methods}

A prospective non-randomized consecutive cross-sectional study was done from July 2004 to June 2006 in the Department of Thoracic surgery, National Institute of Diseases of the Chest and Hospital (NIDCH), Mohakhali, Dhaka. A total number of 43 patients having pulmonary hydatid cyst were selected for this study. Exclusion criteria were co-morbid diseases like acute myocardial infraction and severe diabetes mellitus where surgical intervention is prolonged. Patients were randomly divided into two groups. Group-I involving 23 patients was offered enucleation of cyst with closure of bronchial opening. GroupII involving 20 patients was offered enucleation of cyst with capitonnage. Ethical approval about the study was taken from departmental ethical committee.

Diagnostic workup: Clinical workup include history of petting dog, chest x-ray showing rounded homogeneous opacity in intact cyst, water lily sign present in perforated cysts, computer tomography scan in special cases, indirect hemagglutination assay (IHA) for echinococcosis. Besides, complete blood count, blood sugar, liver and renal function tests are done.

\section{Operative management:}

All the patients were carefully assessed preoperatively. Routine blood tests, chest 
radiograph, electrocardiogram, random blood sugar were done. All patients underwent chest physiotherapy with incentive spirometer before operation. Blood transfusion and nutritional supplement were given when required. Prophylactic antibiotic was started at the time of induction of anaesthesia and continued postoperatively for 10 days.

During this procedure patient was put on pulseoxymeter, non-invasive blood pressure monitor and a good intravenous line. After induction of anaesthesia single lung ventilation was maintained through double lumen endobroncheal tube. A bi-channel foley urinary catheter was introduced and patient was positioned on lateral decubitus position. Standard postero-lateral thoracotomy was done through $5^{\text {th }}$ or $6^{\text {th }}$ rib bed after excising the rib or through interspace after excising a short posterior segment of the rib. The lung was freed from any pleural adhesions. The cyst was covered with water soaked mob to prevent implantation of daughter cysts in the event of rupture. The adventitia was incised carefully to avoid perforation of the cyst. The incision was enlarged in two directions using blunt scissors. The edge of the opening in pericyst is grasped with two fine forceps placed next to each other. The opening of the pericycst was enlarged to its maximum. When the cyst is from one third to one half exposed in this way, the hand is gently pushed beneath the cyst and the remaining part of it is separated from the pericyst by careful finger dissection, until cyst lies in the palm of the hand. It is then placed in a basin. The enucleation of a cyst is not easy when the cyst was large and under tension. In such cases the cystic fluid was aspirated with a large sized needle, then the cyst was opened with a $1 \mathrm{~cm}$ incision and a suction tip entered into the cystic cavity to evacuate the remaining fluid. Germinal membrane was removed with forceps. After flushing the cystic cavity with saline solution, the bronchial openings were closed by muscle pledgeted suture. Some surgeons preferred to keep the cavity open but in some cases cavity was obliterated by capitonnage by suture approximation of the pericystic tissue. Pulmonary resection like lobectomy and segmentectomy was done, when the cyst occupied the whole lobe or has destroyed the adjacent lung. Decortication was performed in patients with pleural complications. In all patients two $32 \mathrm{~F}$ and $28 \mathrm{~F}$ chest drainage catheter was positioned posteriorly and anteriorly in a respective order and were connected with under water seal drainage system. Patients were given Albendazole in doses of $10 \mathrm{mg} / \mathrm{kg}$ body weight as a postoperative prophylactic to prevent recurrence. Postoperative patients were managed accordingly and operative outcome was observed. Patient with satisfactory outcome were discharged on $10^{\text {th }}-12^{\text {th }}$ postoperative day after removing stitches.

\section{Follow up:}

All patients were followed up for six months at monthly interval. In every follow up patients were evaluated clinically and radiologically. Clinically any morbidity such as cough, sputum production, haemoptysis, and febrile episodes were noted. Radiologically any evidence of space infection, any suspected lesion or recurrence of pulmonary hydatid cyst was noted. However all information of the patient were recorded in an individual patient data collection sheet.

\section{Data collection and analysis:}

All relevant data were collected from each participant using predesigned individual data sheet. Collected data were expressed as mean \pm SD. Statistical analysis was done using computer based programme SPSS for windows version 10.0. Unpaired students $T$ test, chisquare test and proportionate ' $z$ ' test were used for statistical analysis. The $\mathrm{p}$ - value of less than 0.05 was considered statistically significant.

\section{Results}

A total of 43 patients of pulmonary hydatid cysts cases were taken in our study. $41.8 \%$ of the patients were between 20-30 years of age followed by $23.3 \%$ between $10-20$ years $18.6 \%$ between $30-40$ years, $9.3 \%$ below 10 years and $7 \%$ was above 40 years of age. The mean age was $25+1.4$ years with the lowest and the highest ages being 7 and 45 years respectively (Table-I). $65 \%$ of the patients were female and the rest $35 \%$ were male. 
Table I

Distribution of the patients by age $(n=43)$

\begin{tabular}{lccc}
\hline Age (years) & No (\%) & $\begin{array}{c}\text { Enucleation of cyst with } \\
\text { closure of bronchial opening }\end{array}$ & $\begin{array}{c}\text { Enucleation of } \\
\text { cyst with capitonage }\end{array}$ \\
\hline$<10$ & $04(9.3)$ & 3 & 1 \\
$11-20$ & $10(23.3)$ & 6 & 4 \\
$21-30$ & $18(41.8)$ & 8 & 10 \\
$31-40$ & $08(18.6)$ & 5 & 3 \\
$>40$ & $03(7.0)$ & 1 & 2 \\
\hline
\end{tabular}

Mean age was $25.0 \pm 1.40$ years: range (7-45) years.

Nearly one-quarter $(23.2 \%)$ of the patients were asymptomatic. The predominant complaints of the patients were chest pain $76.7 \%$ followed by cough without sputum $46.5 \%$, haemoptysis $30.2 \%$ and respiratory distress $27.9 \%$. Cough with sputum $11.6 \%$ (Table-II). Of the 43 patients $63 \%$ were diagnoses by X-ray chest, $28 \%$ by CT scan of chest and rest $9 \%$ by intraoperatively. $65.1 \%$ patients had right lung involvement, $23.3 \%$ had left lung involvement and the rest $11.6 \%$ both lungs involvement (Table-III).

Table II

Distribution of patients by clinical presentation $(n=43)$

\begin{tabular}{lcc}
\hline Clinical Presentation & No & Percentage (\%) \\
\hline Asymptomatic & 10 & 23.2 \\
Cough with sputum & 05 & 11.6 \\
Cough without sputum & 20 & 46.5 \\
Chest pain & 33 & 76.7 \\
Hemoptysis & 13 & 30.2 \\
Respiratory distress & 12 & 27.9 \\
\hline
\end{tabular}

Table III

Distribution of patients side of lung affected

\begin{tabular}{lcc}
\hline Side of lung & No & $\%$ \\
\hline Right & 28 & 65.1 \\
Left & 10 & 23.3 \\
Both & 05 & 11.6 \\
\hline
\end{tabular}

It is observed that in the right lung $6(18.2 \%)$ had upper lobe affected, $5(15.1 \%)$ had middle lobe affected and 22(66.7\%) lower lobe affected. In the left lung $11(73.3 \%)$ had lower lobe involvement, while the rest $4(26.7 \%)$ had upper lobe involvement (Table-IV). It is observed overwhelming majority $95.3 \%$ of the patients had single cyst and the rest $4.7 \%$ had 2 cysts (Table-V).

Table IV

Distribution of patients' side of lung and lobe affected

\begin{tabular}{lccc}
\hline \multicolumn{2}{l}{ Side of lung } & \multicolumn{2}{l}{ Lobe of lung } \\
& Upper (\%) & Middle (\%) & Lower (\%) \\
\hline Right & $6(18.2)$ & $5(15.1)$ & $22(66.7)$ \\
Left & $4(26.7)$ & & $11(73.3)$ \\
\hline
\end{tabular}

\section{Table V}

Distribution of patients by number of cysts

\begin{tabular}{lcc}
\hline $\begin{array}{l}\text { Number of } \\
\text { cysts }\end{array}$ & No. & $\begin{array}{c}\text { Percentage } \\
(\%)\end{array}$ \\
\hline 1 & 41 & 95.3 \\
2 & 02 & 4.7 \\
\hline
\end{tabular}

It demonstrates that $58 \%$ of the patients had intact cysts and the rest $41.9 \%$ exhibited ruptured cysts. $53.4 \%$ of the patients underwent enucleation of the cysts with closure of the bronchial opening, and the rest $46.6 \%$ enucleation of cysts with capitonage (Table-VI).

It has been shown that out of 43 patients $16.3 \%$ developed prolonged air-leakage, $4.5 \%$ had to stay in the hospital for a prolonged time, empyema, bronchopleural fistula and wound infection each was $2.3 \%$. 
It has been found that out of 23 patients who were enucleated with closure of bronchial opening $12.9 \%$ of them developed air-leakage and $4.3 \%$ developed wound infection during postoperative period. Of the 20 patients who were subjected to enucleation of cyst with capitonage, $20 \%$ of them developed air-leakage followed 5\% haemorrhage and 5\% empyema. None of the patient in the former group had to stay in the hospital for $>15$ days, where as $10 \%$ of the latter group had to stay in hospital for $>15$ days. The hospital stay was found to be significantly higher in the later group compared to the former group $(\mathrm{p}<0.05)$ (Table-VII).

It has been shown that comparison of outcome after 6 months of follow up between enucleation of cyst with closure of bronchial opening and capitonnage group. Of the total 43 patients 12 patients were lost during follow up. From the remaining 31 patients none but a single case of capitonnage group developed recurrence of cyst (Table-VIII).

The patient who developed haemorrhage was managed by blood transfusion, bleeding stopped spontaneously. The patient who developed prolonged air leakage managed by chest physiotherapy and tetracyline wash. Patient who developed bronchopleural fistula was managed by tetracycline wash and antibiotics. Patient who developed empyema was managed by local antiseptic and antibiotics after culture sensitivity. Patient who developed wound infection treated accordingly. No patient required re-exploration. Mortality was nil.

\section{Table VI}

Distribution of patients by type of operation (n 43)

\begin{tabular}{lcc}
\hline Type of operation & No. & Percentage (\%) \\
\hline Enucleation of cyst with closure of bronchial opening & 23 & 53.4 \\
Enucleation of cyst with capitonage & 20 & 46.6 \\
\hline
\end{tabular}

Table VII

Comparison of complications between groups $(n=43)$

\begin{tabular}{lccc}
\hline Post-operative & \multicolumn{2}{c}{ Types of operations } & $\mathrm{p}-$ \\
\cline { 2 - 4 } complications & $\begin{array}{c}\text { Enucleation of cyst with } \\
\text { closure of bronchial opening } \\
(\mathrm{n}=23)\end{array}$ & $\begin{array}{c}\text { Enucleation of cyst with } \\
\text { with capitonage } \\
(\mathrm{n}=20)\end{array}$ & $\begin{array}{c}\text { value } \\
\text { Haemorrhage }\end{array}$ \\
Prolong air leakage & 00 & $1(5.0)$ & 0.059 \\
Empyema & $3(12.9)$ & $4(20.0)$ & 0.614 \\
Wound infection & 00 & $1(5.0)$ & 0.059 \\
Bronchopleural fistula & $1(4.3)$ & 00 & 0.121 \\
Hospital stay (> 15 days) & 00 & $1(5.0)$ & 0.059 \\
\hline
\end{tabular}

*Figures in the parentheses denote corresponding \%.

Table VIII

Comparison of outcome after 6 months of follow up between enucleation of cyst with closure of bronchial opening and capitonnage group $(n=31)$

\begin{tabular}{|c|c|c|c|}
\hline \multirow{2}{*}{$\begin{array}{l}\text { Post-operative } \\
\text { complications }\end{array}$} & \multicolumn{2}{|c|}{ Groups } & \multirow{2}{*}{$\begin{array}{c}\mathrm{p}- \\
\text { value }\end{array}$} \\
\hline & $\begin{array}{l}\text { Enucleation of cyst with closure } \\
\text { of bronchial opening }(n=17)\end{array}$ & $\begin{array}{c}\text { Enucleation of cyst } \\
\text { with capitonage }(n=14)\end{array}$ & \\
\hline Cough & 00 & 00 & \\
\hline Haemoptysis & 00 & 00 & \\
\hline Empyema & 00 & 00 & \\
\hline Recurrence & 00 & $1(7.14)$ & 0.21 \\
\hline
\end{tabular}

*Figures in the parentheses denote corresponding \%. Chi-square (x2) test and Student's ' $\mathrm{t}$ ' test were done to analyze the data and the level of significance was 0.05 . 


\section{Discussion}

Pulmonary hydatid cyst is frequently encountered in sheep and cattle raising regions of the world and has been observed most often in Australia, New Zealand, South Africa and Mediterranean countries. Human act as accidental intermediate hosts and harbor cysts, which are most commonly found in the liver and lung but can be discovered in nearly any organ ${ }^{5}$. Bangladesh is also among cattle raising regions. Cows, goats are our common domestic animals. Pulmonary hydatid disease is not uncommon in our country. Surgery is the primary mode of treatment for patients with pulmonary hydatid disease.

In our series, 43 patients having pulmonary hydatid cyst were studied, with the mean age of $25 \pm 1.4$ years. This is consistent with findings of other studies. Turna et al. (2002) $)^{5}$ reviewed 75 patients and showed average age $30.2 \pm 17.4$ years, in their observation. In this study, $65 \%$ of the patients were female and $35 \%$ was male. However in other studies there is male dominance. Hacubrahimoglu et al. (2003) ${ }^{6}$ in his series shown 93 patient, 48 was male and 43 was female. Ahsan et al. (1997) ${ }^{7}$ reviewed 137 patients and showed in male incidence $57 \%$ and female $43 \%$ respectively.

Nearly one quarter $23.2 \%$ of the patients were asymptomatic. They were suspected to have hydatid disease of lung when they attended there physicians with other complaints and subsequently had routine chest $x$-ray and diagnosed pulmonary hydatid cyst. The most predominant complaints of the patients were chest pain $76.7 \%$ followed by cough without sputum $46.5 \%$, haemoptysis $30.2 \%$, respiratory distress $27.9 \%$, fever $23.2 \%$ and cough with sputum $11.6 \%$. Dakak et al. $(2002)^{3}$ in their study of 422 patients showed the presenting complaints of chest pain 32\%, fever 34\%, cough without sputum $56 \%$, cough with sputum $26 \%$, haemoptysis $14 \%$, respiratory distress $11 \%$ and $20 \%$ were asymptomatic. Our observation was more or less similar to their series.

A simple chest roentgenogram is enough to make a diagnosis in most cases of pulmonary hydatid cyst. Round homogenous opacities in the lung parenchyma are characteristics of simple uncomplicated cyst. The water lily or camelot sign is characteristics of perforated cyst and crescent sign is characteristic of air in the cystic cavity. In our study 27 of our cases $62.79 \%$ were diagnosed with a simple roentgenogram. Computerized tomopgraphy was required in $27.90 \%$ and the diagnosis was established intraoperatively in $9.30 \%$. Dakak et al. (2002) ${ }^{3}$ in his study of 422 patients showed chest roentgenogram lead to correct diagnosis in $82.2 \%$ and CT scan $13.27 \%$ cases and MRI in $3.55 \%$ and intraoperatively $0.95 \%$ cases. For diagnosis of pulmonary hydatid cyst our study was similar to this series. However, serological test e.g. the indirect hemagglutination test (IHA) was also used for diagnosis of pulmonary hydatids.

We used standard posterolateral thoracotomy in cases of pulmonary hydatid cyst surgery. In our series $65.1 \%$ patients had right lung involvement, $23.3 \%$ left lung involvement and the rest $11.6 \%$ both lungs involvement. Ahsan et al. $(1997)^{7}$ showed in their series of 137 patients, cyst located in the right lung in $57.06 \%$ left lung $31.06 \%$ and bilaterally $6.05 \%{ }^{7}$. Morar and Feldman $(2003)^{2}$ in their study showed pulmonary hydatid cyst affects right lung in $60 \%$ of the cases. Our study was similar to the above series.

In our study, in the right lung $18.2 \%$ had upper lobe affected, $15.1 \%$ had middle lobe affected and $66.7 \%$ lower lobe affected. In the left lung $73.3 \%$ had lower lobe involvement, while the rest $26.7 \%$ had upper lobe involvement. Dakak et al. $(2002)^{3}$ in their series 422 patients, number of cyst located in right upper lobe was 58 , right middle lobe 46 and right lower lobe 105 cases and in left upper lobe 66, left lower lobe 87 . Hacubrachimoglu et al. $(2003)^{6}$ in their study 96 patients, right upper lobe 19, middle lobe 11 , lower lobe 24 and left upper lobe 21, left lower lobe 21 . The location of the pulmonary hydatid cyst predominance of right lower lobe involvement had been shown in above series. We had also observed same trend of the disease.

It has been shown that majority $95.3 \%$ of the patients had single cyst and rest $4.7 \%$ had 2 cyst. Dakak et al. $(2002)^{3}$ in his 422 patients 296 casespresented solitary pulomonary cyst 
and other cases had multiple cyst in 1 or 2 lobes. In our series we did not found $>2$ cyst in 1 or 2 lobes.

In this study $53.4 \%$ underwent enucleation of the cyst with closure of the bronchial opening without capitonnage and rest $46.6 \%$ underwent enucleation of cyst with capitonnage. The operation was done by almost same group of surgeons. Almost $100 \%$ of the patients had immediate cure. No major fatality like death was observed. Among the 23 patients who were enucleated with closure of bronchial opening, 3 of them developed air leakage, 1 developed wound infection and non of the patient in this group had to stay in the hospital $>15$ days. Of the 20 patients who were subjected to enucleation of cyst with capitonnage, 4 of them developed air leakage followed by 1 haemorrhage, 1 empyema, 2 of this group had to stay in hospital for $>15$ days and 1 developed recurrence. Turna et al. $(2002)^{5}$ showed 71 patients 32 were performed enucleation of the cyst and closure of bronchial openings without capitonnage and 39 patients were performed enucleation with capitonnage. Of the 32 patients who were subjected to enucleation without capitonnage, 4 of them develop air leakage, 1 empyema and none of them developed haemorrhage. Of 39 patients, who were subjected to enucleation of the cyst with capitonnage, 5 of them developed air leakage and 3 of them developed recurrence. Our complication rates were similar to this above series. Ahsan et al. (1997) ${ }^{7}$ and Turna et al. $(2002)^{5}$ reported best operative method is enucleation of cyst without capitonnage. The above procedure was adopted in 23 cases of our group and the results are satisfactory.

Regarding the management of the residual cavity of the pulmonary hydatid cyst, the results of Kuzucu et al. (2003) ${ }^{1}$, Hacubrachimoglu et al. $(2003)^{6}$, Kanat et al. $(2004)^{8}$ favoured the capitonnage method, where residual cavity was obliterated with separate purse string sutures that were placed into the cavity from the deepest level to the surface, as it shorten the postoperative chest tube drainage period and reduce morbidity compared with non capitonnage It is generally agreed, however that the most important point in the management of the residual pericystic cavity is closure of patent bronchial openings. In both of our study groups, surgical intervention primarily consisted of closing all bronchial openings after removal of the membrane of the cyst. Turna et al. $(2002)^{5}$ stated that approximating and suturing cavity edges is not necessary because the pulmonary parenchyma obliterates the space and the surface of the lung at the site of cavity is covered by pleura. Capitonnage provides complete of obliteration of the pericystic cavity to prevent air leak from residual bronchial openings. Without capitonnage, the wall the pericystic cavity is supposed to be covered by epithelial cells for an uncertain length of time. Capitonnage prolongs the operation time and increases the risk of haemorrhage. Enucleation is the preferred method in our institution but is not favoured by others ${ }^{9}$.

In resection surgery, lobectomy was done in two cases due to advanced parenchymal destruction resulting from compression of the cyst, but these two cases were not included in the study. Because our aim was to compare the enucleation of the cyst with closure of bronchial opening and enucleation of the cyst with capitonnage on the basis of surgical outcome.

All patients were discharged with chemoprophylaxis. Albendazole $10 \mathrm{mg} / \mathrm{kg} /$ day for 30 days. 12 patients were lost to follow up. During follow up recurrence developed 1 patient after 6 months of operation in opposite lung in the enucleation with capitonnage group. The patient who had recurrent pulmonary hydatid cyst had a second thoracotomy. Turna et al. 2002 in his series of capitonnage group of 39 patients only 3 developed recurrence ${ }^{5}$. So long term study to see any recurrence is warranted.

\section{Conclusion}

In conclusion, although surgical treatment is effective in patient with ruptured as well as intact cyst for treatment of pulmonary hydatidosis, surgical intervention before rupture of cyst is essential. Regardless of whether symptoms are present, all pulmonary hydatid cysts should be surgically treated as 
soon as they are diagnosed in order to avoid complication.

Our study suggests that each of the surgical methods in the hands of us yielded good results. Capitonnage had no beneficial effect on the surgical management of pulmonary hydatid cysts in terms of postoperative variables and short and long term surgical complication. Management of the bronchial opening is of major importance, whereas capitonnage can be omitted to shorten the operative time.

\section{Recommendations}

1. Enucleation of pulmonary hydatid cyst with closure of bronchial opening should become standard surgical technique for management of pulmonary hydatid cyst.

2. Further long term studies with adequate sample size are required to detect best method of surgical treatment of pulmonary hydatid disease.

\section{References}

1. Kuzucu A, Soysal O, Ozgel M, Yologlu S. Complicated hydatid cysts of the lung: clinical and therapeutic issues. Ann Thorac Surg 2004; 77(4): 1200-4.
2. Morar R, Feldman C. Pulmonary echinococcosis. Eur Respir J 2003; 21(6): 1069-77.

3. Dakak M, Genç O, Gürkök S, Gözübüyük A, Balkanli K. Surgical treatment for pulmonary hydatidosis (a review of 422 cases). J R Coll Surg Edinb 2002; 47(5): 689-92.

4. Mawhorter S, Temeck B, Chang R, Pass H, Nash T. Nonsurgical therapy for pulmonary hydatid cyst disease. Chest 1997; 112(5): 1432-6.

5. Turna A, Yilmaz MA, Haciibrahimoðlu G, Kutlu CA, Bedirhan MA. Surgical treatment of pulmonary hydatid cysts: is capitonnage necessary? Ann Thorac Surg 2002; 74(1): 191-5.

6. Haciibrahimoglu G, Çelik M, Senol C, Orki A, Urek $\mathrm{S}$, Arman B. Surgical treatment of complicated hydatid cysts of the lung. Turkish Respir J 2003; 4(3): 127-30.

7. Ahsan S, Rahman Z, Islam MM, Karim, Islam NM. Surgical management of pulmonary hydatid diseases- a 10 year experience. Chest and Heart Bull 1997; 21(1): 8-12.

8. Kanat F, Turk E, Aribas OK. Comparison of pulmonary hydatid cysts in children and adults. ANZ J Surg 2004; 74(10): 885-9.

9. Yalçinkaya I, Er M, Ozbay B, Uđrap S. Surgical treatment of hydatid cyst of the lung: review of 30 cases. Eur Respir J 1999; 13(2): 441-4.

10. Dogan R, Yuksel M, Cetin G, et al. Surgical treatment of hydatid cysts of the lung: report of 1055 patients. Thorax 1989; 44: 192-9. 